\title{
THE IMITATION GAME: ARE THE MNCS IMMUNE TO MIMETIC ISOMORPHISM?
}

\author{
Darko Tipurić* \\ Ana Krajnović ${ }^{* *}$
}

\begin{abstract}
Organizations tend to shape their practices and policies mimicking those they consider to be successful and legitimate. This phenomenon is called a mimetic isomorphism. Mimetic isomorphism is the result of uncertainties in an environment and of unclear organizational goals. Current institutional isomorphism studies in the organizational sciences have been focused mainly on the impact of mimetic isomorphism on a particular action and the impact of this form of isomorphism on organizational outcomes. The authors of this paper want to examine whether the mimetic isomorphism has an influence on the strategic decision-making process in multinational companies or whether the concept of institutional freedom actually exists as suggested by some authors. Extensive triangulation research was performed and the results of the quantitative and qualitative analysis are presented in this article. The theoretical part of the paper summarizes key ideas of mimetic isomorphism and contributes to the theoretical understanding of this form of isomorphism from the MNC perspective. The empirical part of the paper consists of quantitative and qualitative research. The correlation of the form of mimetic isomorphism with the decision-making process was examined by multiple cross-section regression analysis.
\end{abstract}

KEYWORDS: Mimetic isomorphism, international management, multinational companies, strategic decision-making process

\footnotetext{
*Darko Tipurić, University of Zagreb Faculty of Economics and Business, Croatia; dtipuric@ efzg.hr.

** Ana Krajnović, Privredna banka Zagreb PLC, Croatia; krajnovicana@gmail.com.
} 


\section{INTRODUCTION}

Organizational theorists and scholars have encouraged thinking that organizations operating within the same framework of a complex environment tend to adopt similar, often exactly the same, organizational structures, policies, and practices. They explain this that organizations not only face technological and formal pressures but also those that they interpret separately as the expectations that are being imposed on them. Furthermore, sometimes the demands of the institutional environment are contradictory to the needs of the organization and are directly reflected on the efficiency in operating business. In this case, organizations solemnly adopt institutional requirements; business practices are separated from the real structure all in order to protect the efficiency and survival in the market. The central thought around which institutional isomorphism is developed is that organizations respond to the "rationalized myths" that determine the "good" organization. Over time, these myths provide a range of solutions to organizational problems that organizations accept; this achieves a high degree of institutionalization which ultimately leads to the emergence of institutionalization isomorphism. ${ }^{1}$ Institutional isomorphism facilitates the process of development from idea to realization and influences both business practice and organizational structure. ${ }^{2}$

\section{THEORETICAL BACKGROUND AND HYPOTHESIS}

Organizations tend to shape their practices and policies mimicking those they consider to be successful and legitimate. This phenomenon is called a mimetic isomorphism. Mimetic isomorphism is the result of uncertainties in an environment and of unclear organizational goals. The organization being mimicked is often unaware of the mimicking. However, to the other party, such an organization is a valuable source of ideas to be applied to own business practices. The uncertain environment may be regarded as a force that encourages organizations to mimic one another within the same organizational field. Furthermore, mimetic isomorphism may serve as a practical solution to organizations that are unable to solve their own problems. ${ }^{3}$

\footnotetext{
1 Boxenbaum, E., Jonsson, S.: Isomorphism, Diffusion and Decoupling. The SAGE Handbook of Organizational Institutionalism, London, 2008, p. 84.

2 DiMaggio, P. J.; Powell, W. W: The Iron Cage Revisited: Institutional Isomorphism and Collective Rationality in Organizational Fields. American Sociological Review, 48, 1983, p. 1501.

3 Lee, K.: Pennings, J.: Mimicry and the market: Adoption of a new organizational form, The Academy of Management Journal, 45 (1) 2003, p. 156.
} 
DiMaggio and Powell (1983) conclude that mimetic isomorphism occurs when there is an unclear direction in which the organization is heading and when organizational goals are not clearly defined. The uncertain environment can be seen as a driving force that encourages organizations to mimic one another within the same organizational field.

Organizations look at other organizations as models. They apply almost identical structures to those that are more successful, believing that they will achieve the same success but not taking into account the context in which those structures are applied. ${ }^{4}$ Logically, the mimetic isomorphism is more expressed in those organizations that operate within the same organizational field; for example, banking. Those organizations whose core business is directly and closely related are more likely to appear isomorphic over time. ${ }^{5}$ The uncertain environment is characterized by the advancement and development of technology and strong competitive dynamics. Imitation and mimicking are therefore a practical and effective method that organizations can use to better maneuver within such an environment; research costs are reduced because it enables an organization to implement other organizations' decisions. ${ }^{6}$

Authors suggest three forms of mimetic isomorphism whereby an organization imitates another within the same organizational field: ${ }^{7}$

- Frequency imitation occurs when an organization imitates the actions of the majority organizations presented in the field

- Trait imitation is adopted by organizations that share a common attribute (e.g., size) with other organizations

- outcome imitation occurs when an organization imitates the organization that is a market leader

This triad often appears and applies at the same time. Frequency imitation is applied by a large number of organizations in the field and is largely implemented unknowingly, on a "for granted" principle, and is associated with a

4 Janićijević, N.: Institucionalna organizaciona teorija kao novi istraživački okvir za razumevanje savremenih organizacija, Ekonomske teme, 52 (3) 2014, p. 260.

5 Edwards, J.: Mason, D.: Washington, M.: Institutional pressures, government funding and provincial sport organisations, International Journal of Sport Management \& Marketing, 6 (2) 2009, p. 134.

6 Brouthers, L.E.: O’Donnell, E.: Hadjimarcou, J.: Generic product strategies for emerging market exports into triad nation markets: A mimetic isomorphism approach, The Journal of Management Studies, 42 2005, p. 237

7 Delios, A.: Gaur, A. S.: Makino, S.: The timing of international expansion: information, rivalry and imitation among Japanese firms 1980-2002, Journal of Management Studies, 45 (1) 2008, p. 189. 
critical mass of adopters. Trait imitation is characterized by the comparison of organizations with others in size, performance, or reputation and/or some other attributes. The same authors state that outcome imitation is actually the implementation of the benchmark principle: mimicking those practices of organizations that are most successful in the industry or organizational field.

The emphasis in mimetic isomorphism and the precondition for the appearance of mimetic isomorphism is environmental uncertainty. The greater the uncertainty in the environment, the imitation of other organizations in the field will be more expressed and will consequently serve as a platform for strategic decision making in the organization. Mimetic isomorphism does not guarantee the achievement or improvement of efficiency; moreover, it is even marginal in this case; the greater importance of the occurrence of this form of isomorphism is reflected in the fact that it serves organizations as a mean of improving and strengthening their reputation and image as they tend to be more popular with the organizational field. Also, organizations consciously and voluntarily imitate the structure and actions of other entities in the field in order to gain legitimacy. In doing so, they are potentially improving their access to resources.

Reaching for imitation of certain organizational actions is a common form of behavior among organizations. Organizations mimic each other either in the products they launch or in adopting the same corporate models and organizational structures. By reviewing the relevant literature, imitation has emerged as a leading form of isomorphism, emphasizing the need to understand the reason for this phenomenon to emerge but also the negative consequences that action can result. Numerous theories of imitation have been proposed by business scholars from different disciplines. The authors agree on this: imitation processes are the utmost interesting in environments characterized by uncertainty.

Lieberman and $\mathrm{Asaba}^{8}$ cite two forms of imitative behavior relevant to organizational sciences: (1) imitation based on available information according to which organizations follow those organizations that they consider to have superior and higher quality data and relevant information (they are often mistaken in this generalization) and (2) imitation based on rivalry whereby organizations imitate competitors to achieve parity or limit rivalry.

The interest in testing the hypothesis and applying this theory to multinational companies has been raised by the authors Kostova, Roth, and Dacin ${ }^{9}$ who have

8 Lieberman, M.B: Asaba, S.: Why do firms imitate each other? Academy of Management Review, 31 (2) 2006, p. 357.

9 Kostova, T.: Roth, K.: Dacin, T.: Institutional theory in the study of multinational corporations: A critique and new direction. Academy of Management Review, 33 (4) 2008, p. 996. 
criticized the narrow application of theory postulates to the context of MNCs so far, and in their work have offered a series of provocations to adapt the basic concepts to the application given the nature and specificity of MNCs

Such an application is criticized by the three authors, as specific features of managing and conducting the business of multinational corporations is marginalized. The three re-examine the claims that the survival of an organization depends solely on the level of compliance with the institutional environment minimum managerial discretion is allowed, but it is presumed that legitimacy can be obtained solely by complying with the imposed rules, thus increasing the chance of survival.

The provocations in the work of Kostova et al. (2008) stem from the belief that multinational corporations are embedded in multiple, not clearly defined, and dynamic institutional systems where each system undergoes an institutional process which in the end forms the behavior of an organization. The authors counter the above and suggest that corporations have a dynamic and proactive role in an institutional environment, playing an important agency role as they need to find a way to maneuver, build their position and negotiate in such an environment, which is contrary to the deterministic ideas of neo-institutionalism.

Since multinational corporations have characteristic features in host countries, representing and introducing novelties in the economy, it is less likely they would be expected to adopt local practices. This would be limited to regulatory requirements. In addition to having institutional freedom, subsidiaries of multinational corporations have a wide variety of choices whether they wish to adapt to local practices or follow the instructions from the parent company, depending on what suits them best at a specific moment. Although classic isomorphic effect might be noticed here, this is not the case, as the decision between the local and the parent option is made by the subsidiary and is not the result of compliance with the imposed rules and isomorphic pressures. The combination of multiple institutional pressures contributes to the complexity of the isomorphism of MNCs. ${ }^{10}$

Kostova and co-authors ${ }^{11}$ claim that isomorphism in this case is partly unnecessary and partly improbable - practices imposed by institutions would be similar across organizations. On the other hand, the practices and routines imposed by the headquarters may also be similar to others. The authors conclude that the behavior of subsidiaries of multinational organizations is unpredictable and unique, shaped by multiple institutional inputs. The results would

\footnotetext{
$10 \quad$ Ibid.

11 Ibid.
} 
depend on the choices of the subsidiary itself, depending on what brings more benefit at a certain moment. Isomorphism is therefore not a necessary condition for legitimacy or survival of the company

\section{SAMPLE AND METHODS}

Most empirical research regarding mimetic isomorphism and imitative organizational behavior in the organizational literature has focused on adopting organizational practices and innovations in penetrating a new market. Economists have conducted relatively few empirical researches related to mimetic isomorphism and strategic decision making, and the majority of research on mimetic isomorphism has been placed in the context of FDI. The authors of this paper start from the assumption of limited institutional isomorphism in MNCs and propose the conceptual model of research presented below in the figure. This paper focuses on mimetic isomorphism and it is tested how and if mimetic isomorphism influences the strategic decision-making process in MNCs at all.

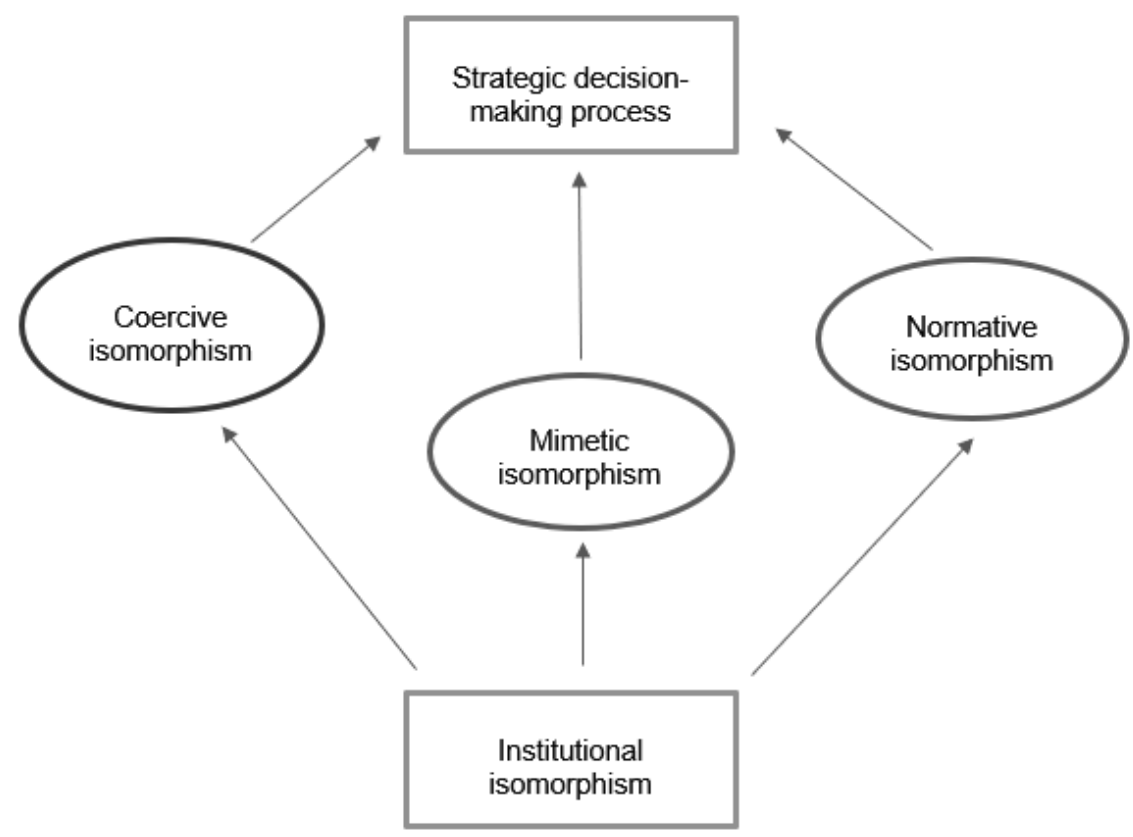


The authors set the hypothesis: Mimetic isomorphism affects strategic decision-making by top management teams of multinational companies in Croatia.

The examination of the hypothesis was carried out by triangulation and the combination of qualitative and quantitative research (the structured anonymous questionnaire was used as the instrument) and in-depth interview. Triangulation is the use of multiple methods or data sources, primarily in qualitative research, to describe a phenomenon as precisely as possible and with as many aspects as possible. ${ }^{12}$

The questionnaire and the interview were used for top management teams of (mostly) foreign-owned multinational companies doing business in Croatia. Purposive sampling was applied in sample selection. Large and mid-sized companies (presidents and members of the board of the companies) were used as a sampling frame. Ownership was considered in addition to the above criterion $-50 \%$ or more of foreign capital in the overall ownership structure. For the purposes of this research, the definition of multinational companies was additionally modified. Intrinsically, a multinational company is a company operating in multiple countries. In this paper, a multinational company is a (foreign) company whose share capital is at least $50 \%$ foreign-owned, i.e. whose majority owner is a foreign company. Domestic multinational companies have been excluded from this research. ${ }^{13}$

This part of empirical research was conducted in the period between March and June 2018. Questionnaires were sent via email to board members, presidents of the boards, or persons having powers of representation according to the Court Register of the Ministry of Justice of the Republic of Croatia, accompanied by a cover letter and instructions on filling-in the questionnaire. A total of 374 questionnaires were sent. Survey sampling resulted in 105 filledin questionnaires, representing a return rate of $28 \%$. A questionnaire with a larger number of questions was used to collect primary data.

Links between mimetic isomorphism and decision-making were examined through multiple regression analysis. Quantitative data were analyzed using the EViews statistical software. Qualitative data was analyzed using Nvivo analysis software. In addition, and due to the nature of the research, descrip-

\footnotetext{
12 Patton, M. Q.: Enhancing the quality and credibility of qualitative analysis. Health Serv Re, 34(5 Pt 2) 1999, p. 1189.

13 Krajnović, A.: The influence of Institutional isomorphism on strategic decision-making process of top management in multinational companies in the Republic of Croatia, Ph.D. Dissertation, Department of Organization and Management, Faculty of Economics and Business, 2019, Zagreb, Croatia.
} 
tive statistics, the method of analysis-synthesis, induction, deduction, and compilation methods were also used.

According to Frumkin and Galaskiewicz ${ }^{14}$ empirical analysis is based on cross-sectional regression. The general form of the model can be written down as follows:

$$
Y_{j}=\alpha+\beta_{j} X_{j}+\mu_{j} Z_{j}+\varepsilon_{j}
$$

$j=1 . .105$ (number of analysed companies)

$Y_{j}$ represents the dependent variable. In this paper, five different dependent variables have been defined, based on which five separate regression models are evaluated. Due to the complexity of the term strategic decision-making and putting it into the context of institutional theory, 5 dimensions of strategic decision-making are used in the research, each dimension representing a single dependent variable: systematical decision-making (model 1), centralization of strategic decision-making (model 2), stalling in strategic decision-making (model 3), rationality in strategic decision-making (model 4), and confidence in strategic decision-making (model 5). $\mathrm{X}$ is the vector of explanatory variables based on which the extent to which multinational companies analyzed in the paper are exposed to mimetic pressures (isomorphism) is tested, i.e. how they affect the decision-making process. The direction of the effects is defined by the prefix of parameter $\beta \mathrm{j}$. In line with the above explanations and definitions of various forms of isomorphism, independent variables have been constructed as independent answers or arithmetic means of answers to selected measures of isomorphism.

Since the uncertain environment is the main driver for the company's mimetic behavior, mimetic pressures on strategic decision-making were examined through selected measures of mimetic isomorphism, as suggested by Parmigiani (2007): ${ }^{15}$ volume uncertainty, technological uncertainty, and performance uncertainty.

The author states that the uncertain environment influences the organizational choices and decisions it makes and includes the potential for change in the environment as well as the unpredictability of the behavior of the individual

14 Frumkin, P.: Galaskiewicz, J.: Institutional Isomorphism and Public Sector Organizations, Journal of Public Administration Research and Theory, (14) 3 2004, p. 290.

15 Parmigiani, A.: Why Do Firms Both Make and Buy? An Investigation of Concurrent Sourcing. Strategic Management Journal, 28 (3) 2007, p. 295. 
or business in general. A greater degree of uncertainty leads to difficult adaptation and a more difficult evaluation of performance itself, which often leads to the internationalization of activities since hierarchical authority allows for better coordination and monitoring of activities and results. ${ }^{16}$

Volume uncertainty is the first measure of mimetic isomorphism used in research. It represents a form of uncertainty in an environment that potentially influences the decision-making and strategic choices of businesses and refers to the unpredictability of demand and the inability to accurately predict specific events. Another measure of mimetic isomorphism is technological uncertainty. A greater degree of uncertainty in technological change will result in more significant challenges of adaptation and coordination but will at the same time increase the risk of obsolescence of the same technology, requiring additional investment. The third measure of mimetic isomorphism is performance uncertainty, which can potentially influence the strategic decision-making process. The measure refers to difficulties in predicting, for example, how a product or service will be accepted in the future. A high degree of performance uncertainty requires financial capital and investment in performance monitoring. Accordingly, the decision-makers often imitate practices due to the lack of resources or ignorance to deal with a specific situation resulting from an uncertain environment. ${ }^{17}$

\section{DISCUSSION}

The table below shows the results of the influence of mimetic isomorphism on the strategic decision-making process, which is defined by three explanatory variables, volume uncertainty, technological uncertainty, and performance uncertainty.

\footnotetext{
16 Ibid.
}

17 Ibid. 
Table 1. Results of regression analysis of the influence of mimetic isomorphism on the dimensions of strategic decision making

\begin{tabular}{|l|c|c|c|c|c|}
\hline & Model M1 & Model M2 & Model M3 & Model M4 & Model M5 \\
\hline Constant & $1.31^{* * *}$ & $3.48^{* * *}$ & $3.06^{* * *}$ & $3.48^{* * *}$ & $2.93^{* * *}$ \\
\hline $\begin{array}{l}\text { The main explanatory } \\
\text { variables }\end{array}$ & & & & & \\
\hline volume uncertainty & -0.02 & 0.07 & -0.08 & 0.08 & -0.05 \\
\hline technological uncertainty & 0.00 & -0.21 & $-0.04 *$ & -0.19 & 0.00 \\
\hline performance uncertainty & 0.02 & -0.12 & -0.02 & -0.01 & 0.02 \\
\hline & & & & & \\
\hline Control variable & & & & & \\
\hline activity & $0.09 *$ & $0.12^{*}$ & 0.04 & 0.03 & -0.05 \\
\hline orientation & $-0.23^{* *}$ & $-0.30^{*}$ & 0.12 & 0.15 & -0.01 \\
\hline rivalry & 0.10 & $-0.27 *$ & $-0.23^{* *}$ & $-0.23 * *$ & 0.04 \\
\hline size & -0.09 & -0.02 & 0.02 & 0.04 & 0.07 \\
\hline R-square & 0.17 & 0.18 & 0.29 & 0.19 & 0.17 \\
\hline *** significance at 1\%, ** significance at 5\%, * significance at $10 \%$ & & \\
\hline
\end{tabular}

The dependent variable in the first model is systematical decision-making. The results of the analysis show that no explanatory variable of mimetic isomorphism has a statistically significant effect on systematical decision-making, so interpretation of these parameters makes no statistical sense. In the second model, the dependent variable is the centralization of strategic decision making. The results of the analysis show that no explanatory variable of mimetic isomorphism has a statistically significant effect on the centralization of the strategic decision-making process, so interpretation of these parameters makes no statistical sense. Since Models 1 and 2 have no statistically significant effect of the main explanatory variables, quality and adequacy tests will not be performed for models 1 and 2 . In the third model, the dependent variable is stalling in strategic decision-making. The results of the analysis show that only the technological uncertainty variable has a statistically significant effect on the dependent variable, with a significance level of $10 \%$. The estimated parameter indicates that the presence of this type of pressure reduces the stalling in making strategic decisions. Other explanatory variables of mimetic isomorphism do not have a statistically significant effect on the dependent variable, so interpretation of these parameters does not make statistical sense. 
The coefficient of determination indicates that the model explains $29 \%$ of the variation in the dependent variable, which in this type of cross-section analysis suggests that the model has relatively high explanatory power. Rationality in the strategic decision-making process is the dependent variable in the fourth model. The results of the analysis show that no explanatory variable has a statistically significant influence on rationality in making strategic decisions, so interpretation of these parameters makes no statistical sense. In the fifth model, the dependent variable is confidence in strategic decision-making. The results of the analysis show that no explanatory variable significant influence on confidence in making strategic decisions, so interpretation of these parameters makes no statistical sense.

The results of the regression analysis of the effect of mimetic isomorphism on the five dimensions of the strategic decision-making process show that in most cases the effect of this type of pressure is statistically insignificant. Only one of the three explanatory variables, technological uncertainty, has a statistically significant effect in one of the five models, at a significance level of $10 \%$. Therefore, it can be concluded that mimetic isomorphism does not have a significant influence on strategic decision making.

The results of the regression analysis in the quantitative part of the research showed that in most cases mimetic isomorphism is statistically insignificant. The results of the qualitative part of the research support the results of the regression analysis.

All respondents stated that they regularly monitor competitors' business (often daily meetings), although interviewees stated that they perceive as leaders in their industry. Competitors' business data are collected from secondary sources of data, and they do not conduct their own research. Keeping track of competitors' work enables them to learn from others, to generate creative ideas and business models that can potentially be leveraged and modified in their own businesses. More importantly, monitoring competition's business activities can show changes in the direction of the industry regarding global trends. Foreign subsidiaries operating on the territory of the Republic of Croatia serve as a testing ground for domestic companies that lack both resources and knowledge for such a venture. Interestingly, that all the respondents stated that they are almost not interested in the local competition, but only the global competition in the European Union market is observed.

Although competition's work is monitored, excessive focus on the competition is not a characteristic of leading companies analyzed in this interview. If the strategic direction is clear - which in this case it is - direct and frequent mimicking of competition's moves is non-existent. Subjects state that competition's moves are not blindly adopted. Such adoption depends on the situation. Global 
trends and moves made by global competitors are adopted more frequently, so such strategic moves are monitored more closely. As for predictability of decisions, subjects noted that decisions are derived from internal needs of the company and that the industry is neither creative enough, nor does it allow too much freedom, due to both the legal framework and the industry and/or parent company itself. Due to the above, mimetic isomorphism does not affect strategic decision making in multinational companies.

\section{LIMITATIONS}

Limitations of this research partially refer to its methodological aspects. The use of questionnaires as a research instrument, relying on subjective opinions of subjects and the application of mostly perceptive measures raise the issue of bias. Although it is a common and routine practice in the research of this type, an attempt has been made to partially mitigate the disadvantages of this method and the biases resulting from its application by applying complementary methods and in-depth interview on a significantly smaller sample, considering that members and presidents of boards are difficult to reach due to their positions in the organizational hierarchy and their availability. Secondly, a larger number of answers from one analyzed company - answers from more than one member of the board - would further minimize bias.

\section{CONCLUSION AND IMPLICATION}

The research of the effect of mimetic isomorphism on the strategic decision-making of top management teams in multinational companies in the Republic of Croatia from a scientific point of view encompasses the unexplored area of strategic management discipline. From the point of view of strategic management, the theoretical approach of mimetic isomorphism has been poorly explored in foreign literature, while it has been almost neglected in the domestic literature. Therefore, the motive for studying mimetic isomorphism in multinational companies and its influence on strategic decision making is a logical move.

The results of the research of mimetic isomorphism on the strategic decision-making process of MNC subsidiaries indicate that the work of competitors is monitored, however, imitation of their decisions is not the case in the examined sample. Competition in the domestic market is not such as to interfere nor influence the strategic decisions, but there is a trend of monitoring global competition and adopting trends beyond the boundaries of the local environment. 
The specificity of this research is to emphasize the role of the top management teams of the subsidiaries of multinational companies in the Republic of Croatia in the creation and decision making under uncertainty from the perspective of mimetic isomorphism. Independent implementation of both theoretical and empirical research resulted in the creation of new knowledge and values in order to stimulate reflection on the construction of new ways of understanding business dynamics and strategic decision-making processes.

\section{LITERATURE}

1. Boxenbaum, E.: Jonsson, S.: Isomorphism, Diffusion and Decoupling. The SAGE Handbook of Organizational Institutionalism, London, 2008, p. 78-98.

- DOI: https://doi.org/10.4135/9781849200387.n3

2. Brouthers, L.E.: O’Donnell, E.: Hadjimarcou, J.: Generic product strategies for emerging market exports into triad nation markets: A mimetic isomorphism approach, The Journal of Management Studies, 42, 2005, p. 225-245.

- DOI: https://doi.org/10.1111/j.1467-6486.2005.00495.x

3. Delios, A.: Gaur, A. S.: Makino, S.: The timing of international expansion: information, rivalry and imitation among Japanese firms 1980-2002, Journal of Management Studies, 45 (1), 2008, p. 169-195.

- DOI: https://doi.org/10.1111/j.1467-6486.2007.00742.x

4. DiMaggio, P. J.: Powell, W. W.: The Iron Cage Revisited: Institutional Isomorphism and Collective Rationality in Organizational Fields. American Sociological Review, 48, 1983, p. 147-160.

- DOI: https://doi.org/10.2307/2095101

5. Edwards, J.: Mason, D.: Washington, M.: Institutional pressures, government funding and provincial sport organisations. International Journal of Sport Management \& Marketing. 6 (2), 2009, p. 128-149.

- DOI: https://doi.org/10.1504/IJSMM.2009.028798

6. Frumkin, P.: Galaskiewicz, J.: Institutional Isomorphism and Public Sector Organizations, Journal of Public Administration Research and Theory, (14) 3, 2004, p. 283-307.

- DOI: https://doi.org/10.1093/jopart/muh028

7. Haunschild, P.: Miner, A.: Modes of interorganizational imitation: the effects of outcome salience and uncertainty, Administrative Science Quarterly, 42 (3), 1997, p. 472-500.

- DOI: https://doi.org/10.2307/2393735

8. Huang, X.: Gattiker, T.F.: Schroeder, R.G.: Do competitive priorities drive adoption of electronic commerce applications? Testing the contingency and institutional views, Journal of Supply Chain Management, 46 (3), 2010, p. 57-69.

- DOI: https://doi.org/10.1111/j.1745-493X.2010.03198.x 
9. Janićijević, N.: Institucionalna organizaciona teorija kao novi istraživački okvir za razumevanje savremenih organizacija, Ekonomske teme, 52 (3), 2014, p. 251270.

10. Kostova, T.: Roth, K.: Dacin, T.: Institutional theory in the study of multinational corporations: A critique and new direction, Academy of Management Review, 33 (4), 2008, p. 994-1006.

- DOI: https://doi.org/10.5465/amr.2008.34422026

11. Krajnović, A.: The influence of Institutional isomorphism on strategic decision-making process of top management in multinational companies in the Republic of Croatia, Ph.D. Dissertation, Department of Organization and Management, Faculty of Economics and Business, Zagreb, 2019, Croatia

12. Lee, K.: Pennings, J.: Mimicry and the market: Adoption of a new organizational form, The Academy of Management Journal, 45(1), 2003, p. 144-162

- DOI: https://doi.org/10.2307/3069289

13. Lieberman M.B: Asaba S.: Why do firms imitate each other? Academy of Management Review, 31 (2), 2006, p. 366-385.

- DOI: https://doi.org/10.5465/amr.2006.20208686

14. Parmigiani, A.: Why Do Firms Both Make and Buy? An Investigation of Concurrent Sourcing, Strategic Management Journal, 28 (3), 2007, p. 285-311.

- DOI: https://doi.org/10.1002/smj.580

15. Patton, M. Q.: Enhancing the quality and credibility of qualitative analysis, Health Serv Res. 34(5 Pt 2): 1999, p. 1189-208. 